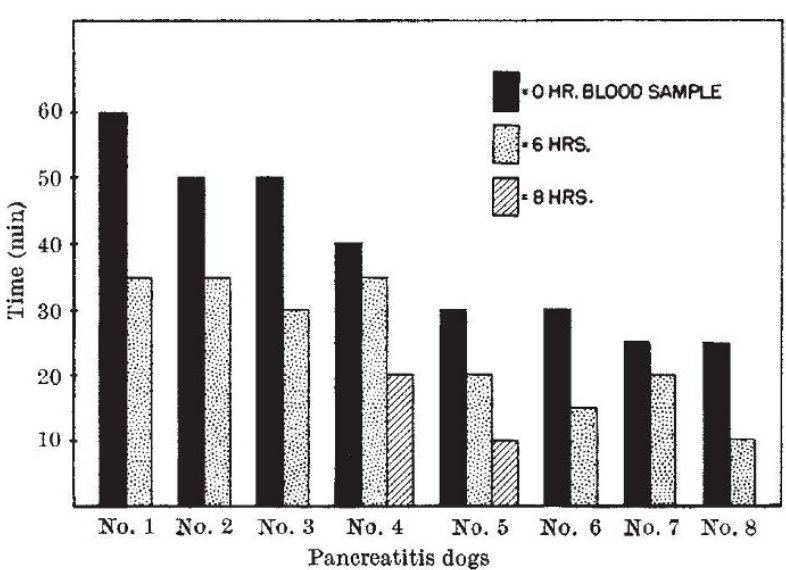

Fig. 1. Time for complete inhibition of $0.05 \mathrm{mcg}$ of bradykinin in $0,6-\mathrm{h}$, and 8-h blood samples from eight dogs with bile pancreatitis

an inactive form ${ }^{1}$. The balaneo botween available kininase and kinin production thus becomes extremely important in this disease.

Reports have been made of increased kinin activity ${ }^{2-4}$ and of decreased kinin precursor ${ }^{3}$ during experimental pancreatitis in the dog, but to our knowledge changes in plasma kininase levels have not been studied.

Eight mongrel dogs were anaesthetized with sodium pentothal (10.5 mg per lb.). Bile panereatitis was produced by injecting 10 c.c. of the bile of the dogs into the major pancreatic duct under pressure. The portal vein was cannulated through the splenic voin and blood was collected at $0,2,4$ and $6 \mathrm{~h}$; in two dogs a specimen was also collected at $8 \mathrm{~h}$.

5 c.c. of oxalated blood was centrifuged at $37^{\circ} \mathrm{C}$ and 40,000 r.p.m. for $15 \mathrm{~min} ; 0.5$ c.c. of plasma was then diluted with 19.5 c.c. of buffered saline solution, and 5 c.c. of this mixture was incubated with an equal amount of a standard solution containing $0.05 \mathrm{meg}$ of bradykinin (kindly supplied by Sandoz Pharmaceutica!s, Hanover, New Jersoy). In a rat uterus bioassay system, unresponsive to histamine, serotonin and catecholamines, vasoactivity of the incubated mixture was determined at 5 -min intervals until no activity was detectable.

Plasma kininase levels increased during the first $8 \mathrm{~h}$ of pancreatitis in all the dogs. The time for total inhibition of $0.05 \mathrm{meg}$ of bradykinin decreased from a mean control time of 39 min to a mean of $23 \mathrm{~min}$ in the 6-h pancreatitis specimen (Fig. 1). No change in the level of plasma kininase was detected during sham pancreatitis.

This investigation was supported in part by funds from the U.S. Public Health Service.

$$
\begin{aligned}
& \text { F. Warren Nugent } \\
& \text { Winifredo A. Atendido* } \\
& \text { Manuel B. Bulan }
\end{aligned}
$$$$
\text { Arnoldo J. MacDonatd }
$$

Lahey Clinie Foundation,

Boston, Massachusetts.

* Present address: 8321 Dangal Street, Sta. Mesa, Manilla, Ptsilippines.

${ }^{3}$ Fasciolo, J. C., Acta Physiol. Lat. Amer., 14, 170 (1964). 2 Thal, A. P., Kobold, E. E., and Hollenberg, M. J., Amer. J. Surg., 105, 708

${ }^{3}$ Ryan, J. W., Moffat, J. G., and Thompson, A. G., Arch. Surg., 91, 14 (1965).

' Nugent, F. W., and Atendido, W. A., Amer. J. Gastroenterol., 43, 437 (1965).

\section{Alveolar Deposition of Aerosols on the Moon and in Outer Space}

IT was recently suggested ${ }^{1}$ that, on the Moon, man will be more susceptible to infection by aerosols containing bacteria because the smaller gravitational field will lower the filtration efficiency of the upper respiratory tract. The reduction in upper respiratory tract deposition will be caused by a reduction in the sedimentation velocity

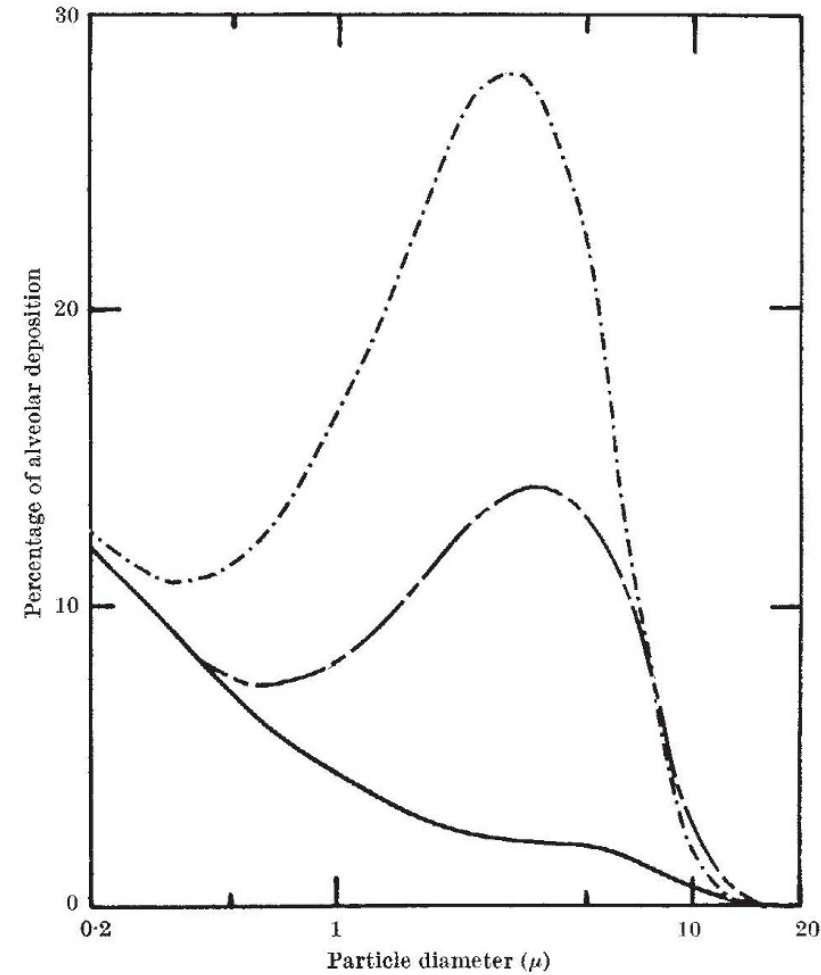

Fig. 1. Percentage of inhaled particles deposited in the alveolated regions of the lung as a function of particle size, for unit density spheres. Upper curve, Terrestrial deposition; middle curve, lunar deposition;

of the aerosol particles. The other mechanisms for upper respiratory tract deposition, Brownian diffusion and im. paction, will be unaffected, but the former is of negligible importance for particles greater than about $1 \mu$.

I recently published details of a method for calculating alveolar deposition as a function of particle size ${ }^{2,3}$. The computations were performed on an electronic computer, and recalculations based on a different gravitational acceleration were easily performed. The results are shown in Fig. 1, for a tidal volume of 500 c.c., a 3 -sec linear symmetrical breathing cycle without pauses, and a functional residual capacity of $2 \mathrm{l}$. It is seen that alveolar deposition on the Moon does exceed terrestrial alveolar deposition, as predicted, in the region of particle-sizes greater than $7 \mu$. However, the difference is not so great as might have been expected, and this is due to the fact that, on the Moon, a higher proportion of those particles which penetrate the upper respiratory tract are exhaled from the lower respiratory tract without being deposited there. This is even more true in the complete absence of gravity, and alveolar deposition in this case is everywhere lower than it would be on either the Moon or the Earth. J. M. BeEckmans

Department of Physiological Hygiene, University of Toronto.

${ }^{1}$ Muir, D. C., Nature, 209, 921 (1960).

" Beeckmans, J. M., Canad. J. Physiol. Pharmacol., 43, 157 (1965).

${ }^{3}$ Beeckmans, J. M., Ann. Occup. Hyg., 8, 221 (1965).

\section{Technique for investigating Binding of Labelled Thyroxine by Human Serum}

Techniques using two-dimensional electrophoresis for the investigation of the proteins of human serum have been reported in the past ${ }^{1,2}$. However, these techniques are rarely used because they do not offer advantages over other procedures ${ }^{3}$. The present communication contains a report of a new two-dimensional technique of paper electrophoresis which was used to achieve a better separation of the proteins of human serum. The same technique 